\title{
REMODELLING AND REPOSITIONING OF COURT'S MEDIATION IN INDONESIA
}

\author{
R. Benny Riyanto \\ Faculty of Law Diponegoro University Semarang \\ Email : dr.bennyriyanto@yahoo.com
}

\begin{abstract}
This article is intended to explain the failure of the use of mediation in Indonesia, particularly mediation which is integrated with the court (court connected mediation). The focus of the problem in this study is about the ideal model of court connected mediation as a strategy to achieve the hope of strengthening and to maximize the function of judiciary institutions in resolving dispute in Indonesia. A method of socio-legal research is used to reveal things that make mediation has not worked effectively in resolving civil case in court. This study resulted that the practice of mediation in civil court is very limited, especially dealing with a model applied by mediators, so it is not always appropriate to the situation faced by the parties in disputes. Moreover, although the Supreme Court Regulation allows comediation, in practice, it is never implemented. Even court connected mediation has become part of the dispute because it has been registered and published to public. So that it becomes a non-legal factor that influence the parties to reach agreement.
\end{abstract}

Keywords : mediation, mediator, civil case, model, court.

\section{Introduction}

\subsection{Background}

This article intends to explain the failure of the use of mediation in Indonesia, especially, which is integrated with the court mediation or the court connected mediation. In Indonesian law terminology, the court connected mediation is called as "mediation procedures in court". This court connected mediation was begun in early of 2000 in Indonesia, in particular, for civil cases were sued to the district court. Initially, this court connected mediation is corroborated by the Supreme Court Rule Number 02 of 2003 on mediation 
procedures in court. Article 2 section (1) of this rule is a provision which, for the first time, require all civil cases filed in the district court to be first resolved through reconcilement with the help of mediator. This provision also constructs a series of new procedure for civil disputes settlement which had never been done before.

Five years later, the regulation was repealed and replaced by Supreme Court Rule Number 01 of 2008 on mediation procedures in court which is expanding the application of mediation in court. One of the expansions is the use of mediation at all levels of dispute settlement. Moreover, there is an enactment of provision restricting action of mediator through "the mediator's code of conduct" which must be obeyed. This change is based on a number of weaknesses of court mediation rule of 2003. The failures of mediation's usage in court for, at least, the first ten years of application has motivated to carry out reformation of law of mediation in court in 2016.

In 2016, the Supreme Courts changed the Rule of 2008 with Supreme Courts Rule Number 1 of 2016 on Mediation Procedures in Court. One of considerations of the establishment of the Supreme Court Rules Number 1 of 2016 on Mediation Procedures in Court (hereinafter referred to Supreme Court Rules), is that the previous Rule is less optimal to meet the needs of the implementation of useful mediation and to be able to improve the success of mediation in court.

The different between the current rule and the repealed rule is related to the shorter period of mediation, the good faith requirements, and sanctions for parties who do not have a good faith during the mediation. The lack of good faith is associated to the rejection of lawsuit by the judge. Even, the judge can be blamed for violating the legislation if he does not order the disputants to do mediation. The failures of mediation problems in Indonesia is very complicated, not only a matter of procedure, but also involving the mind-set of every disputants towards the mediation as the procedure.

Conceptually, in a rather different technical design, in fact, mediation has been developed in Indonesia, whether in the forms of traditional law, habits, or 
religious law. The main similarity to mediation is on the peaceful dispute settlements between parties based on shared interest of each party. The main difference is on the existence of the third party who facilitates the dispute settlements. In the tradition and customs of Indonesian society, the local government usually takes important roles, while in mediation, mediator is the third party which is neutral and not take sides, besides being professional. The conflict or disputes in Indonesian society's tradition tends to be inseparable part of their daily life which marks the communal relationship. Thus, the third party's role who governs or has the power in the society is very important.

The integration of mediation process into court system provides a hope in strengthening and maximizing the function of court institution in settling the disputes, especially to solve the stacking civil cases in court and creating a simple, fast and inexpensive principles of courts, as stipulated in article 2 section (4) Acts number 02 of 2009 on Judicial Power. In practice, it is a fact that the success of court connected mediation is not optimal. This fact leads to the practical explanation that integrating mediation into the civil court has made the process longer and not simple. So, the civil dispute settlements process in court is more expensive and experiencing distortion.

Based on the data of Semarang's District Court in the last 3 years, starting from 2013 to 2015, the total of civil cases trials in Semarang District Court can be seen as follows:

a) $2013: 479$ cases
b) $2014: 482$ cases
c) $2015: 520$ cases

This total of cases shows a tendency of escalation year by year. The increasing number of cases has a potential of accumulation cases starting from the Court of first Instance (District Court), which is supported by average number of not more than 32 judges. It means each judge has 16 cases to solve in a year. It is not an easy thing to solve since the formality/steps of settling a civil matter based on the civil procedural law is very complex, so, it takes a long time to solve the 
case. These cases are not balance to the success of settling the cases through mediation in court. Based on the court's data, the number of civil cases which can be solved by mediation are:
a. $2013: 15$ cases
b. $2014: 8$ cases
c. $2015: 7$ cases

The data explains the success of mediation tends to decrease year by year. It is ironic, because the total of the cases is increasing, while the success of case settlement is decreasing. These facts also prove that the effectiveness of the case settlement through mediation in court is still very low, less than $2 \%$ (two percent). This condition is ironic with the hopes of integrating mediation institution into court is to decrease the burden of court in solving the cases. This reality explains that mediation is only a myth of conflict transformation. Moral transformation and social vision - from the individualistic to relational and interactive conception - of accepting the mediation in court is not successful. As what has been stated by Robert A. Baruch Bush and Joseph P. Folger, academics/ scholars and thinkers think that even if the individual ethics from modern Western culture is the biggest achievements of social order in the past, it becomes a hope and necessitation to move further and reaching full integration of individual freedom and social awareness in relational social order which is made through new forms from process and social institution. ${ }^{46}$

The failures of using mediation in Indonesia is not only at mediation integrated to court, but also to the mediation outside of the court. It means that between the institutions to settle the existing dispute - court and arbitration, mediation becomes least choice of dispute settlements. Therefore, it is ironic to Indonesian tradition or customs which have some institutions in solving conflict. This condition also shows that there is an inaccuracy or even mistakes in the

46 Robert A. Baruch Bush dan Joseph P. Folger, 2005, The Promise of Mediation, The Transformative Approach to Conflict, San Francisco: Jossey-Bass, p.24. 
attempts of offering mediation as one of the forms of dispute settlements, especially which is integrated to court.

This failure of court connected mediation in Indonesian is unique and out of what has been described in research results in other countries. Thus, the experience of mediation in Indonesia gives a confirmation of unique situation and strategies offered. This failure is not fully caused by internal factor related to mediator strategy, or, the choices of model shown through Acts regulating the mediation. Outside the factors, external factors like psychology of the nation in dispute, law tradition, especially practice in court which is harmonized with mediation without the basis of local wisdom. A matter of harmonization with local wisdom has been implicitly allowed by the Supreme Court Rules through the provision of its openness of involving experts, public figures, religious leaders, or traditional leaders. But, this involvement is facultative which depend on the agreement of all parties. Moreover, conceptually, structurally, and in methods cannot be meant by the convergence between the foreign model and the receiver.

Based on the condition, the integration of civil court connected mediation in Indonesian court needs a reconstruction to improve the agreement achievement among the disputants. The hopes of this process is the court connected mediation can become an ideal and effective forum in settling disputes, so, disputes is not continued to a long legal process. The negligence of unproductivity in dispute settlements through court connected mediation potentially has consequence to raise negative assumption toward the process of dispute settlements in court.

Without neglecting the success of mediation in court, mediation then becomes a proforma, since the acts/legislation necessitates mediation before the examination session. This causes the disputes settlement process prolonged, the cost becomes more expensive, and the process becomes more complicated.

\subsection{Research Question}

Based on the background, the problem is How the ideal model of court connected mediation as a potential strategy to reach the hopes to strengthen and maximize the function of court/legal institution in settling disputes in Indonesia. 


\subsection{Research Methods}

The dispute settlements model using mediation is a part of alternative dispute resolution (ADR) besides other models, such as negotiation and conciliation which were born in the third wave of dispute settlements institution. Theoretically, there are two models commonly used for settling disputes, like ${ }^{47}$ :

a. First, adjudicative dispute settlements model. This approach is an approach to reach justice through the adversary system and using coercion in managing disputes and resulting a win-lose solution for the disputants. In adjudicative model, besides court (litigation settlement) which was born in the first wave, and arbitration in the second wave.

b. Second, the non-adjudicative dispute settlements model. In this model, achieving justice prefers "consensus" approach and efforts to reconcile the interest of the disputant and aims to get the dispute settlement toward win-win solution. The non-litigation disputes settlement is often called as ADR which fills the third wave.

Ehrmann states that "There are two principal forms of resolving legal disputes throughout the world. Either the parties to a conflict determine the outcome themselves by negotiation, which does not preclude that a third party acting as a mediator might assist them in their negotiations. Or, the conflict is adjudicated, which means that a third, and ideally impartial party decides which of the disputants has the superior claim "48. These forms are used and sometimes intertwine in settling civil, criminal and administrative cases. ${ }^{49}$ Based on the statements, Steven Vago affirms that the main mechanism in settling disputes can be depicted in a span of continuum from negotiation to adjudication. In negotiation, the participation is voluntary and every disputant arrange the settlement themselves. The next continuum is mediation, where the third party facilitates the settlement and helps every party in reaching voluntary agreement. At the end of

\footnotetext{
47 Adi Sulistiyono, 2006, Mengembangkan Pradigma Non-Litigasi di Indonesia, Surakarta, UNS Press, page. 6.

48 Steven Vago, 2011, Law and Society, 10th Edition, New Jersey, Prentice Hall, p.256.

49 Ibid.
} 
continuum, the adjudication (either judicial or administrative) - every parties was coerced to be involved, and the cases was given a verdict by the judge, every parties can be represented by advocates, formal procedures, and the result can be enforced under the law. Similar process to adjudication is arbitration, which is more informal. ${ }^{50}$ Christopher W. Moore depicts conflict management continuum and settlements approach as follows:

\section{Figure 1. Continum of Conflict Management and Resolution Approaches ${ }^{51}$}

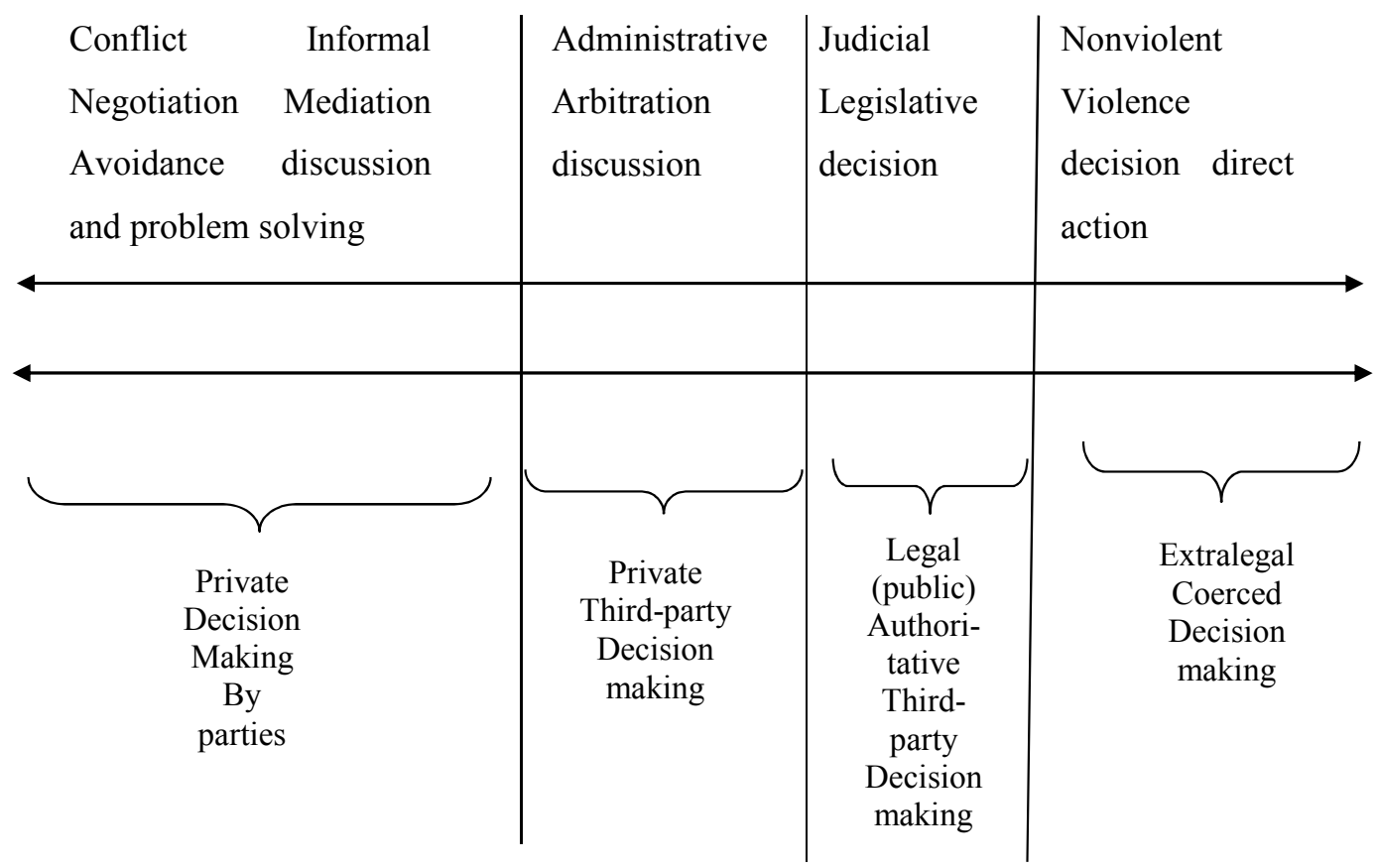

The figure explains that the conflict in the society has several ways of settlements and they can be an option. Each choices have different formality of the process, privacy of the approach, involved party, the authority of the third party, verdicts types resulted, and the coercion level given by or to certain disputant. The left side of the continuum is informal, private procedure is only involving disputants. Meanwhile on the right side, a party imposes coercion and often in form

\footnotetext{
$50 \quad$ Ibid., p.258-259.

51 Christopher W. Moore, Op. Cit., p.6.
} 
of public action to force the opponent to follow (obey). ${ }^{52}$ The use of the model is determined by the dispute settlements purposes, complexity, and social status. Each model has strength and weakness. Litigation model or court process is based on the dispute settlements' paradigm of upholding rule of Law. The existence of court is intended to become a facilitative tool to enforce law by providing justice access to the disputants. The problem of law in Indonesia is that litigation dispute settlement has excessive formality, not efficient and not effective, expensive, potential alignment, and the verdicts are often disappointing those who seek justice. in that context, ADR (alternative dispute resolution) becomes an alternative offering more efficient, simple, and confidential processes, either in the form of negotiation or mediation. Normally, when the negotiation or mediation fails to offer, the choices of settlement moves to arbitration or court.

\section{Research Methods}

The focus of the problem in this study is about the ideal model of court connected mediation as a strategy to achieve the hope of strengthening and to maximize the function of judiciary institutions in resolving dispute in Indonesia. A method of socio-legal research is used to reveal things that make mediation has not worked effectively in resolving civil case in court.

\section{Result and Discussion}

\subsection{The Limitation of Court Mediation Model}

In Indonesia, generally, provision regarding mediation is regulated under Acts Number 30 of 1999 on Arbitration and Alternative Dispute Resolution (UU Arbitration and ADR), but it is not regulated further, even it is not mentioned as court connected mediation. Special provision of mediation in court is regulated by Supreme Court Rules Number 1 of 2016 on Mediation Procedure in Court (also known as Supreme Court Rules).

The idea of Arbitration and Alternatives Dispute Resolutions (ADR) Acts contains of controversy. On one hand, mediator freedom to use model variation is

$52 \quad$ Ibid., p.7. 
shown; while on the other hand, mediation model is limited. Technically, mediation is becoming very strict. The impression shown about mediator freedom to use various model is actually an incorrect impression since what is exempted by Arbitration and ADR Acts and the Supreme Court Rules is the technical model that has been specified limited. It means, both Arbitration and ADR Acts and Supreme Court Rules follow the paradigm of "limited model" and do not provide "model and technical freedom space". It is clearly stated on Article 6 section (2) of Arbitration and ADR Acts:

Dispute or different opinion settlement through Alternatives Dispute Resolutions referred to section (1) resolved in a meeting directly attended by the parties in a maximum period of time 14 (fourteen) days a and the result is set forth in a written agreement.

Supreme Court Rules regulates a wider term compared to the provision on Article 6 section (2) of Arbitration and ADR Acts about the possibility of mediation model application. Article 5 section (3) of Supreme Court Rules states that "Mediation can be carried out through media of communication, long distance audio visual that enables all parties to see each other and listen directly and participate in the meeting." Supreme Court Rules is considered to be more advanced than the Arbitration and ADR Acts, but it raises a question "does not it mean Supreme Court Rules contradict to the Arbitration and ADR Acts?" In spite of this contradiction, it shows that it is the time for the Arbitration and ADR Acts to be revised so that it does not raise multi-interpretation about the contradiction. The preference to revise the Arbitration and ADR Acts is caused by its incompatibility with the nature of mediation as a more flexible dispute settlement model and technical - compared to adjudicative court or arbitration.

Conceptually, the possibility of "long distance mediation" application based on Supreme Court Rules is one of the models related to "joint meetings". So, the question is, "why is other "joint meetings" model not adopted?" A more essential question to ask is, "why are other models not adopted, so that the court connected mediations are more varied?" In order to provide the mediator a freedom to 
construct a strategy, Supreme Court Rules does not mention "joint meeting" that acontrario limits the strategy. This causes an ineffective mediation in the court in terms of models and types of mediation. This condition confirms a factor that influences the effectiveness of mediation as stated by Tobias Böhmelt that:

With regard to mediation effectiveness, the existing literature frequently emphasizes three factors. The first one pertains to characteristic of the dispute, i.e. its intensity and duration or the issues at stake. The third factor describes the mediators as such or the type of mediation pursued. ${ }^{53}$

Variety concept of mediation process, according to Laurence Boulle, can be classified based on 3 (three) models or types, namely: (1) variation in relation to the number of mediators, (2) variations in relation to the joint meetings, and (3) variations in relation to the separate meetings). ${ }^{54}$

The first model (variation in relation to the number of mediators) is divided into some types of process, such as: (a) solo mediation and (b) the co-mediation process. Solo mediation basically uses a single mediator. The co-mediation process uses more than one mediator.

The second model (variations in relation to the joint meetings) is divided into some types of process, namely: (a) multiple meetings, (b) different venues, and (c) telephone conferences. Multiple meetings are important because most of the mediations do not reach the final conclusion in only one meeting and postponement is needed. Postponement has some functions in mediation process. Multiple meetings enable the parties to obtain further information, like evaluation, professional advice, re-evaluating their situation, and planning the proposal and response. It also enables the mediator(s) to propose the limitation of the secrecy, to evaluate the progress, and to plan the next strategy. Nevertheless, postponement has some weaknessess, among other, the regression of some accepted agreement.

53 Tobias Böhmelt, 2011, International Mediation Interaction Synergy, Conflict, Effectiveness, Germany: VS Research, pg.16.

${ }^{54}$ Laurence Boulle, 1996, Mediation Principles, Process, Practice, Adelaide, Butterworths, pg.113118. 
Different venues are related to space and logistic reason. The questions from each side can be used as a rotation to show the side of the party. Telephone conferences can be done telephonically for geographic distance reason, limited sources, and legal requirements.

The third model (variations in relation to the separate meetings) includes: (a) shuttle mediation, (b) separate meetings with advisers and parties. Shuttle mediation is a separate meeting without a face-to-face meeting among the parties. The mediator moves from one party to another; or becoming the means of communication and negotiation of the parties. This model is applicable in antagonist condition and in a condition in where the meeting tends to be contraproductive. The second type, separate meetings with advisers and parties, explains the flexibility of mediation process. This type enables the mediator to do a separate meeting with the lawyer or advisor of the parties. This process points out the proper role of the advisor in the mediation, without losing his/her reputation. If the mediator is an advocate, he/she can discuss some legal issues with the advisors from all parties.

In terms of strategic freedom and discretion to choose the model, mediation can be integrated with the court that enables the mediator to choose one among the models and strategies that is suitable with the situation in Indonesia. Joint meeting can be suitable for a certain situation, but it may not be suitable for other cases. In many cases whose parties do not conduct a face-to-face meeting for any reason they, indeed, need another model other than joint meeting.

Theoretically, mediation model can be classified into settlement model/compromise, facilitative model, therapeutic style, and evaluative model. The strictly categorization acceptance of those models in Indonesia leads to a court mediation distortion in evaluative model. Susanti Adi Nugroho determines that court mediation gives more attention on evaluative model. This model is marked by: (a) the parties come and expect the mediator to give an understanding that if the case is continued, the party who wins or loses will be determined, (b) more focus on rights and responsibilities, (c) usually the mediator is an expert in certain field, 
or an expert in law because the focus of the approach is the rights. Mediator tends to provides a solution and information about the law in order to lead to a proper final result, (d) give suggestions or advices for the parties in the form of legal advice or a solution offered by the mediator, so that it contains some weaknesses, (e) the parties feel that they do not own the final result that is signed by all parties. $^{55}$ This determination makes the mediation becomes less subdued. The failures caused by an incompatible model with the situation of the disputants disadvantaged prominence, demand, psychological condition, legal relationship as the basis of the dispute - can not be matched by model variations, so there is no other way to settle the dispute.

The explanation above leads us to an understanding that the model of court connected mediation needs a reconstruction aimed to achieve an optimal result, namely the success as a significant effort of dispute settlement. Based on the developed model, a variation of model applicable in Indonesia needs to be loosen. It means to change the strict mediation rules that limit the model and strategy to give the mediator a freedom to choose model and strategy that is suitable with the case.

The problems of ineffective court connected mediation are caused by the failure in creating an integrated model, including the failure of the mediator in the mediation process. A confidential mediation should be integrated with a civil judicial which is opened to the public. It causes the emergence of legal cultural problems for the mediator, advocate, and the parties in dispute in mediation practice. As has been stated by Tony Whatling that assumption that culture influences the success of the mediator in mediation practice. ${ }^{56}$ Steven E. Barkan, based on socio-legal point of view, states the influence of social and individual factors. The society has a different point of view towards some certain aspects of

55 Susanti Adi Nugroho, Mediasi sebagai Alternatif Penyelesaian Sengketa, Telaga Ilmu Indonesia, Jakarta, 2009, pg.63-64.

56 Tony Whatling, 2016, "Difference Matters: Developing Culturally Sensitive Mediation Practice", in the Journal of Mediation \& Applied Conflict Analysis, Maynooth University, pg.(48-58) 51 . 
their structure and culture, which reveals the difference in preferences of dispute settlement method, ${ }^{57}$ like explaining why some societies or individuals prefer a mediation to others. ${ }^{58}$ If it is categorized as special situation, then, as has been stated by Christoper W. Moore, it needs to prepare a strategy to respond the situation.

We now turn to an examination of contingent strategies and activities interventions and preventions by mediators to respond to unique or unusual situations, conflict dynamics, or parties, which are not present in every negotiation or dispute. Though it is impossible to identify or describe all the situations that may require contingent activities by mediators, and details about their actual moves, there are a number of them that are common enough to merit description. ${ }^{59}$

Moore also mentions some writers who describe unique situations and potential contingency strategies that can be chosen by the mediator to overcome the failure in mediation practice, as has been said by Fisher, Maggiolo, and Wall. The situations and strategies are:

a) Problems with parties working together in joint sessions that may require private meetings or caucuses;

b) Situations involving time and timing that may require time management by mediators

c) Situations requiring mediator influence and potential strategies and techniques;

d) Problems with parties' bases of power and means of influence, and mediator techniques to address and manage them;

e) Issues related to gender, working with women, and women as mediators;

f) Problems related to past, resent, and future causes of conflicts, and grand strategies to address them;

7 Steven E. Barkan, 2009, Law and Society, An Introduction, New Jersey: Pearson, Prntice Hall, pg.104.

58 Ibid

59 Christopher W. Moore, 2014, The Mediation Process, Fourth Edition, San Francisco: JosseyBass, pg.489. 
g) The presence of strong values and how they may be handled. ${ }^{60}$

The seven potential causes of a failure according to Moore have some strict rules in Supreme Court Rules, so the mediator in the court can not develop their creativity to adjust with the condition of the parties who have legal dispute. Even the violation towards the court procedures is resulted in court verdict void $a b$ initio.

\subsection{Co-mediation and Ineffective Telephone Conference}

In relation to the numbers of mediator, Supreme Court Rules enables the use of co-mediation process model. It is regulated on Article 19 of Supreme Court Rules as follows:

a) The parties have a right to choose a mediator or more which is listed in Mediator List in the court.

b) If there is more than one mediator in the mediation process, the division of tasks of the Mediator is determined and agreed by the Mediators.

c) Further requirements about Mediator List as mention on section (1) is regulated in the Chairman of Supreme Court decision.

Although co-mediation process is possible according to Supreme Court Rules, it is never or seldom applied in the court, especially in the relation with the choice to use non-judge mediator service, and the mediator's fee is paid by all parties or based on their agreement. The use of co-mediation process needs to be empowered and encouraged because it has some potential advantages (aside from its potential disadvantage), such as:

a. Additional Resources: co-mediation involves the multiplication of mediator resources in all mediation facet. It enables the co-mediator becomes the complement of each power, to consult each other and avoid being fatigue.

$60 \quad$ Ibid 
b. Division of labor: co-mediation enables the division of labor, especially during initial stage of the mediation when the mediator needs to mediate in comprehensive range as his/her essential function in a limited period of time.

c. Matching of mediators with parties: co-mediation model enables gender equality, race, age, or group attribute of the parties and mediators in order to offer acceptability, and satisfaction for the parties.

d. Selection of professional background: co-mediation enables the parties to select more than one person with professional background, who can contribute in the success of mediation. For example, in the legal, science, technology, environment, and construction dispute. Other variations can be offered a welltrained co-mediator in the mediation and other co-mediators have a wide experience on the cases being disputed. ${ }^{61}$

Co-mediation model does not work well in court connected mediation because the court determines the parties to have only one mediator. It is caused by the limited numbers of mediator in the court in relation to "free" service, without any additional cost. Except, if the parties are willing to spend any additional cost for the second mediator, especially mediator who is not provided by the court. It increases the cost of a case. Moreover, the court through its presiding judge never offers a possibility to choose co-mediation by the parties in dispute.

Other models which are not mentioned on Arbitration and ADR Acts and Supreme Court Rules are in relation with "joint meetings", which in mediation session is conducted in different venues. In relation with "separate meetings", court connected mediation needs to be loosen with the possibility of "shuttle mediation" application or separate meetings with legal advisers and parties.

As well as the type of teleconference mediation, Supreme Court Rules enables the application of "long distance mediation", as has been regulated on Article 5 section (3), "Mediation can be carried out through long distance audio visual communication media that enables all parties to see and listen to each other

61 Laurence Boulle, Op. Cit., pg.115-116. 
live , and participate in the meeting." Conceptually, the use of the terms "long distance mediation" may have a different definition with "telephone conference mediation" because "long distance mediation" may have the same meaning as "shuttle mediation" (the kind of "separate meeting"). Even though this variation is possible to do, it does not have a pattern yet and needs some further experiments.

The provision on Article 5 section (3) of Supreme Court Rules cannot be a "choice" because practically there is a priority on "the responsibility to attend the mediation in person". As has been regulated on Article 6 section (1) of Supreme Court Rules, "The parties must attend the mediation with or without a legal advisor". The priority to attend the mediation causes the court connected mediation in Indonesia trapped in a strict technical and not developed. In relation with the cost, it does not reduce the court fee.

\subsection{Court Mediation Repositioning}

Positioning court connected mediation as a facility to replace and optimize the requirement on Article $130 \mathrm{HIR}$ / Article $154 \mathrm{Rbg}$ that regulate peace evidently has a serious impact. Court connected mediation is, in fact, also combined with the concept of "peace". The Peace based on Article 130 HIR has passed through the case register and announcement by the court.

This condition, hypothetically, causes the defendant feel ashamed, even challenged, so that the defendant especially, is difficult to give a concession in the bargaining process/discussion during mediation process. The reality is similar with one of the reason the emergence of ADR, such as the judicial process cannot keep the confidentiality of the parties legal relation that causes the dispute. So, when the mediation is positioned in an opened-process that has been announced by the court, mediation process creates cynicism for the parties. Laurence Boulle states "mediation is often promoted in terms of the privacy of the mediation sessions and the confidentiality of what transpire there." 62

62 Ibid, p.41 
In order to overcome that problem, the obligation of "openness" session from the court connected mediation needs to be considered to prevent the wounding of the main character, in a more confidential meaning. Mediation must have been done before the case is registered by the court, so that the dispute has not been announced to the public yet. Hypothetically, it can decrease the burden of the opened characteristic of the dispute, because the parties have not been defamed as a result of law suit that has not stated his/her act against the law or wanprestatie. In this case, the re-purification of the court connected mediation is a necessity.

The re-purification of the court connected mediation is not easy because we still use HIR/Rbg, that regulates the openness characteristic of all the dispute in the court, including the peace based on Article $130 \mathrm{HIR} /$ Article $154 \mathrm{Rbg}$. It reflects the urgency to reform of HIR and Rbg.

The use of court connected mediation model still needs an opened space, the model is not the only way to achieve our goal. Esin Orucu states:

“Cultural diversity' reflecting on legal systems must be appreciated since 'diversity' and 'flexibility', being related to freedom of choice, are part of democracy, the one fundamental value upheld by all in at least the Western world. Aims such as 'harmonization, 'integration' and 'globalization' show acceptance of the existence of differences but, nevertheless, aspire to produce sameness. Yet the distinctiveness and mutuality should also be emphasized within the concept of 'harmony'. "63

It means, the use or the choice of a more opened-model still needs the harmonization with culture of recipient society. The plurality of Indonesia with the traditional pattern of dispute settlement that create peace needs to get part in the court connected mediation.

Although Indonesia, traditionally, recognizes "discussion or musyawarah", which in the context of dispute settlement means an effort or peaceful way between the parties, but it does not entirely equal to mediation. In certain parts, discussion has some fundamental differences with mediation. They may principally, be equal,

63 Esin Orucu, "Critical Comparative Law, Considering Paradoxes for Legal System in Transition”, EJCL, Vol.4.1., June, 2000, http://www.ejcl.com., 23rd of March 2010. 
but technically there is discrepancy. Therefore, It makes the mediation is not easy to accept, and need a modification in strategy and model level. As a comparison, in Rwanda, there is "indigenous 'mediation-like", like Rwanda's gacaca, which is a combination of admission, and the formation of public and group decision, with a ritual and clemancy as an effort to form new relationships. ${ }^{64}$

\section{Conclusion}

The effort that can be done to achieve an ideal model of court connected mediation, among others, enables the openness of the use of court connected mediation model, which is impossible in some requirements of mediation in Indonesia, especially court connected mediation. Besides, repositioning of mediation attached to the requirement on Article $130 \mathrm{HIR} /$ Article $154 \mathrm{Rbg}$ to keep confidentiality becomes important. Nevertheless, harmonization is still needed to get rid of inequality between original and target model, by combining mediation and local elements.

\section{References}

Adi Sulistiyono. (2006). Mengembangkan Pradigma Non-Litigasi di Indonesi. Surakarta: UNS Pres.

Böhmelt, Tobias. (2011). International Mediation Interaction Synergy, Conflict, Effectiveness. Germany: VS Research.

Bush, Robert A. Baruch dan Folger, Joseph P. (2005). The Promise of Mediation, The Transformative Approach to Conflict. San Francisco: Jossey-Bas.

Cane Peter dan Kritzer, Herbert M., Ed. (2010). The Oxford Handbook of Empirical Legal Research. New York: Oxford University Press.

Christopher W., Moore. (2014). The Mediation Process : Practical Strategies for Resolving Conflict. San Fransisco : Jossey Bass Publisher.

Esin Orucu. (2010). Critical Comparative Law, Considering Paradoxes for Legal System in Transition. EJCL, Vol.4.1., June, 2000, http://www.ejcl.com., $23^{\text {rd }}$ March.

${ }^{64}$ Carrie J. Menkel-Meadow, "Dispute Resolution”, dalam Peter Cane dan Herbert M. Kritzer, Ed., 2010, The Oxford Handbook of Empirical Legal Research, New York: Oxford University Press, pg.612. 
Laurence Boulle. (1996). Mediation Principles, Process, Practice. Adelaide: Butterworths.

Susanti Adi Nugroho. (2009). Mediasi Sebagai Alternatif Penyelesaian Sengketa. Jakarta: Telaga Ilmu Indonesia.

Suzanne McCorkle dan Melanie J. Reese. (2005). Mediation Theory and Practice. USA: Pearson Education.

Stephen B. Goldberg, ed. (2003). Dispute Resolution, Negotiation, Mediation, and Other Process. New York: Aspen Publishing.

Steven Vago. (2011). Law and Society, 10th Edition. New Jersey: Prentice Hall.

Acts Number 30/1999 regarding Arbitration and Alternative Dispute Resolution

Acts Number 4/2004 regarding The Power of Judges

Supreme Court Rules Number 1/2016 regarding Court Mediation 